\title{
Conflict and tuberculosis in Sudan: a 10- year review of the National Tuberculosis Programme, 2004-2014
}

Sara A. Hassanain ${ }^{1 *} \mathbb{D}$, Jeffrey K. Edwards ${ }^{2,3}$, Emilie Venables ${ }^{2,4}$, Engy Ali ${ }^{2}$, Khadiga Adam ${ }^{5}$, Hafiz Hussien ${ }^{1,5}$ and Asma Elsony ${ }^{1}$

\begin{abstract}
Background: Sudan is a fragile developing country, with a low expenditure on health. It has been subjected to ongoing conflicts ever since 1956, with the Darfur crisis peaking in 2004. The conflict, in combination with the weak infrastructure, can lead to poor access to healthcare. Hence, this can cause an increased risk of infection, greater morbidity and mortality from tuberculosis (TB), especially amongst the poor, displaced and refugee populations. This study will be the first to describe TB case notifications, characteristics and outcomes over a ten-year period in Darfur in comparison with the non-conflict Eastern zones within Sudan.

Methods: A cross-sectional review of the National Tuberculosis Programme (NTP) data from 2004 to 2014 comparing the Darfur conflict zone with the non-conflict eastern zone.

Results: New case notifications were $52 \%$ lower in the conflict zone $(21,131)$ compared to the non-conflict zone $(43,826)$. Smear-positive pulmonary TB (PTB) in the conflict zone constituted $63 \%$ of all notified cases, compared to the non-conflict zone of $32 \%(p<0.001)$. Extrapulmonary TB (EPTB) predominated the TB notified cases in the nonconflict zone, comprising 35\% of the new cases versus $9 \%$ in the conflict zone $(p<0.001)$. The loss to follow up (LTFU) was high in both zones (7\% conflict vs $10 \%$ non-conflict, $p<0.001)$ with a higher rate among re-treatment cases (12\%) in the conflict zone. Average treatment success rates of smear-positive pulmonary TB (PTB), over ten years, were low (65-66\%) in both zones. TB mortality among re-treatment cases was higher in the conflict zone (8\%) compared to the non-conflict zone (6\%) $(p<0.001)$.

Conclusion: A low TB case notification was found in the conflict zone from 2004 to 2014. High loss to follow up and falling treatment success rates were found in both conflict and non-conflict zones, which represents a significant public health risk. Further analysis of the TB response and surveillance system in both zones is needed to confirm the factors associated with the poor outcomes. Using context-sensitive measures and simplified pathways with an emphasis on displaced persons may increase access and case notification in conflict zones, which can help avoid a loss to follow up in both zones.
\end{abstract}

Keywords: Sudan, Conflict, Non-conflict, Tuberculosis programme, Performance, Darfur, Outcomes, Operational research

\footnotetext{
* Correspondence: sarahazim@gmail.com

${ }^{1}$ The Epidemiological Laboratory, House 34, Street 53, New Extension,

P.O.BOX 13595, Khartoum, Sudan

Full list of author information is available at the end of the article
} International License (http://creativecommons.org/licenses/by/4.0/), which permits unrestricted use, distribution, and reproduction in any medium, provided you give appropriate credit to the original author(s) and the source, provide a link to the Creative Commons license, and indicate if changes were made. The Creative Commons Public Domain Dedication waiver (http://creativecommons.org/publicdomain/zero/1.0/) applies to the data made available in this article, unless otherwise stated. 


\section{Background}

Conflicts impact health infrastructure and human resources, which can hinder disease prevention and control measures. This escalates the burden of communicable diseases, such as tuberculosis (TB) [1, 2]. In addition, conflicts cause the displacement of populations and impair access to healthcare. This can increase TB transmission, worsen patient outcomes and lead to increasing rates of drug resistance [3, 4]. A study conducted in Nepal found that the poor uptake of TB services was due to war-associated factors [1]. Furthermore, high treatment initiation delays and self-treatment have also been observed in the Somali conflict region of Ethiopia [5]. Displaced populations and refugee settlements are frequently exposed to TB risk factors, which can lead to increased transmission. An example is in Lebanon, where a $27 \%$ rise in TB incidence was attributed to the increase in the Syrian refugee population [6]. Likewise, a study in El Salvador reported the incidence rate of TB among internally displaced persons (IDPs) to be three times higher than the reported rate across the rest of the country [7]. Furthermore, refugees and IDPs are at a higher risk of acquiring multi-drug resistant (MDR) TB due to treatment interruption [8, 9]. TB associated mortality has been reported to be higher in conflict zones, as demonstrated by a study from Guinea Bissau that found TB mortality to be three times higher among conflict cohorts in comparison to non-conflict cohorts [10]. A study from Kenya has shown that TB caused $20 \%$ more deaths within children aged 5 years and younger within the internally displaced population, in comparison with the children of regular residents [11]. TB was attributed to the deaths of approximately $26 \%$ of adult IDPs in Somalia and $38 \%$ to $50 \%$ of all deaths among adult refugees in refugee camps in eastern Sudan [4].

Sudan is an extremely turbulent country that has suffered from years of civil conflicts, including the North-South and Darfur crises [12]. Sudan has a low health expenditure (6.2\% of GDP) and has an estimated TB incident rate of 117 per 100,000 individuals [13]. Notified TB cases have remained relatively constant over the past decade, within the range of 19,817 to 22,097 . Moreover, Sudan has a low human immunodeficiency virus (HIV) prevalence, which was reported to be $0.3 \%$ as of 2015 . However, the prevalence of MDR TB, as reported by Sudan's National TB programme (NTP) in 2012, was $19 \%$ in re-treatment cases and $1.8 \%$ in new cases [13]. Another study in north-eastern Sudan reported an MDR prevalence of $6 \%$ among new TB cases [14].

The Darfur conflict officially started in 2003, but clashes flared with a greater intensity in 2004, leading to a humanitarian crisis. There have been approximately 1.9 million IDPs since the beginning of the conflict. The highest levels of violence were experienced in 2014 when more than 430,000 people were newly displaced. There have also been reports of deprived health situations, prevalent TB risk factors, low primary health care (PHC) coverage, inadequate health system accessibility and depleted human resources within the Darfur region [15]. Data associated with TB in Darfur are limited, and there is an ever-increasing need to address this within the vulnerable conflict-ridden population. To our knowledge, there are no studies analyzing TB data, over a 10-year period, at a national level within Sudan. In particular, there has not been a comparison between a conflict zone and a non-conflict zone within Sudan. Our hypothesis is that conflicts negatively affect TB prevention and control measures. This study aims to compare overall TB case notifications, treatment outcomes and trends between the conflict region of Darfur and the non-conflict region of eastern Sudan from 2004 to 2014, to determine the TB control status in the conflict zone.

\section{Methods \\ Study design}

This is a descriptive cross-sectional review of Sudan's NTP surveillance aggregated data from 2004 to 2014, within a conflict zone (Darfur) and a non-conflict zone (Eastern Sudan).

\section{General setting}

Sudan is a Sub-Saharan African country with an estimated population of 40 million. It is ranked at 167 out of 188 countries in the Human Development Index (HDI) and has 4.8 million people needing humanitarian assistance because of conflict, environmental and food insecurity factors [16].

\section{Specific setting}

The Darfur conflict zone is a border region that covers an area of 493,180 $\mathrm{km}^{2}$ in western Sudan. It has an estimated population of six million people, including five states (North, West, South, East and Central Darfur). The conflict has caused an internal displacement of people, of which at least $60 \%$ are children living in camps. It has led to Darfur having approximately 140,000 refugees [17].

The non-conflict zone is a border region in eastern Sudan that covers an area of $324,773 \mathrm{~km}^{2}$. It includes three states (Kassala, Gadarif and the Red Sea) with a combined population of approximately 5 million and has not experienced any conflict during 2004-2014. There are over 135,000 refugees and asylum seekers residing in camps [17].

Two zones were chosen for this study to examine the hypothesis that conflicts have a negative impact on $\mathrm{TB}$ 
indicators. The zones were selected because of their similarities, which are as follows:

- A mixed population of settled peasant and nomadic herders

- Prevalent poverty, famine and inequalities at social and political levels, including a lack of access to adequate quality health services

- Widespread inter- and cross-border mobility and displacement, which increase the risk of communicable diseases

- Targeted humanitarian response for vulnerable IDPs and refugees in partnership with local authorities, State Ministries, United Nations (UN) agencies, international and national Non-Governmental Organizations (NGOs)

- Severely compromised health systems

- TB management and surveillance systems functioning similarly across both zones

\section{TB management and control}

TB prevention and control activities are coordinated by the NTP in both the conflict and non-conflict zones. The NTP is managed by a central unit located in Khartoum, with sentinel coordination in each state. Expansion has been achieved through the decentralisation of diagnosis and treatment into TB management units (TBMUs). The services have been integrated into the existing healthcare system, which includes recording, reporting, training, supervision and health education. This allows coverage of an average of 100,000 people per TBMU.

TB laboratory activities are performed in the regular laboratory network composed of the national reference laboratory in the capital Khartoum and state quality control laboratories. They provide cultures and drug susceptibility. TB patients are treated free of charge and in accordance with the World Health Organization's (WHO) recommended Directly Observed Treatment, Short Course TB control strategy (DOTS). TB services are provided through health services in hospitals, health centres, assigned NGOs and health insurance centres [18]. In the Darfur conflict zone, approximately $81 \%$ of TBMUs are governmental, $9 \%$ are run by military troops, $8 \%$ by NGOs and the remaining are insurance centres. In the Eastern zone, approximately 85\% of TBMUs are governmental, $9 \%$ are NGOs, $4 \%$ are military centres, and $2 \%$ are insurance centres. NGOs are crucial in strengthening the TB community systems in both zones by tracing patients lost to follow up, conducting contact tracing and active case finding. Moreover, they also handle referrals with the help of trained community health volunteers.

The surveillance system is standard across Sudan, including the conflict-associated zones. Data collection occurs at TBMU's, which utilise patient cards and registers, with the reporting of aggregated data to state and central authorities occurring quarterly. This reporting gathers information regarding the case, age, gender and outcomes. MDR TB care is provided in the Abu-Anga central hospital in the state of Khartoum. In 2013-2014, a change of NTP management was introduced with oversight provided by the Communicable and NonCommunicable Disease Department (CNDC).

\section{Study population}

The study included all centrally registered TB patients from the two study zones, which are Darfur and the Eastern states, between 2004 and 2014.

\section{Data collection and analysis}

The data were validated at various points, including the point of entry, at the central NTP level, and through inspections of registries for missing data and consistency. Quarterly aggregated data (number of cases per TB type, age and gender) were reviewed by year and state for conflict and non-conflict zones, covering the period of 2004 to 2014. The data were processed before the analysis to validate the consistency between the total number of TB cases (new and re-treated), as well as cohort registered treatment outcomes. The variables that were collected include the number of registered cases, the epidemiological characteristics of registered cases (gender and age), the type and category of TB, and treatment outcomes. Standardised definitions for these variables were consistent with the International Union Against Tuberculosis and Lung Disease (The Union) and the WHO.

\section{Statistical analysis}

The data were extracted from the NTP reporting platforms into Microsoft Excel (Microsoft Corp, Redmond, Washington, USA), computerised and entered in STATA version 13.0 (Stata Corp, College Station, Texas, USA). Using descriptive frequency analysis, the demographic and clinical characteristics, and treatment outcomes were analysed in relation to the conflict and non-conflict zones. The data were cross-tabulated using the chi-square test to examine relationships. A T-test was applied and a $p$-value lower than 0.05 was considered significant. The associated trends comparing conflict and nonconflict zones were calculated.

\section{Results}

\section{Case notification}

Between 2004 and 2014 a total of 21,131 new TB cases were reported in the conflict zone (Darfur) versus 43,826 in the non-conflict zone. There were 1822 notified TB re-treatment cases from the conflict and 2024 from the non-conflict zone, as shown in Table 1. 
Table 1 Case notification classification and treatment outcomes of new and re-treatment tuberculosis, TB, cases in conflict and nonconflict zones in Sudan, 2004-2014

\begin{tabular}{|c|c|c|c|}
\hline Clinical characteristics (New cases) & Conflict zone $N=21,131$ (100\%) & Non-conflict $N=43,826(100 \%)$ & $p$-value \\
\hline PTB smear positive & $13,283(63)$ & $14,016(32)$ & $<0.001$ \\
\hline PTB smear negative & $5309(25)$ & $12,680(30)$ & $<0.001$ \\
\hline EPTB & $1963(9)$ & $15,378(35)$ & $<0.001$ \\
\hline PTB (not done) & $576(3)$ & $1392(3)$ & 0.073 \\
\hline Treatment outcomes (New cases) & Conflict $N=20,326$ n (\%) & Non-conflict N = 43,826 n (\%) & \\
\hline Treatment success ${ }^{\mathrm{a}}$ & $13,498(66)$ & $28,645(65)$ & $<0.001$ \\
\hline Died & $422(2)$ & $1124(3)$ & $<0.001$ \\
\hline Treatment failure & $139(1)$ & $156(<1)$ & 0.703 \\
\hline LTFU & $1379(7)$ & $4709(10)$ & $<0.001$ \\
\hline Transferred out & $592(3)$ & $2141(5)$ & 0.001 \\
\hline Not evaluated & $4296(21)$ & $7051(16)$ & 0.526 \\
\hline Clinical characteristics (Re-treatment cases) & Conflict zone $N=1822$ (100\%) & Non-conflict N = 2024 (100\%) & \\
\hline After Relapse & $912(50)$ & $1412(70)$ & 0.005 \\
\hline After LTFU ${ }^{a}$ & $669(37)$ & $314(16)$ & 0.014 \\
\hline After Failure & $155(8)$ & $148(7)$ & 0.804 \\
\hline Others $^{b}$ & $86(5)$ & $150(7)$ & 0.276 \\
\hline Treatment outcomes (Re-treatment cases) & Conflict zone $N=1822$ n (\%) & Non-conflict N = 2024 n (\%) & \\
\hline Treatment success ${ }^{a}$ & $693(38)$ & $911(45)$ & $<0.001$ \\
\hline Died & $146(8)$ & $121(6)$ & $<0.001$ \\
\hline Treatment failure & $163(9)$ & $122(6)$ & $<0.001$ \\
\hline LTFU & $218(12)$ & $202(10)$ & $<0.001$ \\
\hline Transferred out & $200(11)$ & $243(12)$ & 0.986 \\
\hline Not evaluated & $402(22)$ & $425(21)$ & 0.713 \\
\hline
\end{tabular}

a PTB Pulmonary TB, EPTB Extrapulmonary TB, LTFU Loss to follow up, Treatment success $=$ Cured and treatment completed cases

ball cases that are registered whom their definition is not consistent with other re-treatment definitions

As shown in Fig. 1, the non-conflict zone surpassed the conflict zone in the number of notified new cases per year with a range of 4387-3698 versus 2734-1196, between 2004 and 2014 . The average notification rates of new cases during this time were 88 and 37 per 100,000 population in the non-conflict and conflict zones respectively. Furthermore, the average notification rates of re-treatment cases between 2004 and 2014 were 4.5 and 3 per 100,000 population in the non-conflict and conflict zones respectively.

\section{Demographic characteristics}

Of the reported new cases, $10 \%$ were in children aged 15 years and younger in the conflict zone, compared to $5 \%$ of cases in the non-conflict zone. Age was unrecorded for $18 \%$ and $22 \%$ of new TB cases in the conflict and non-conflict zones respectively. Gender was not recorded for almost $29 \%$ and $30 \%$ of the new TB cases in the conflict and non-conflict zones respectively. Within the new TB cases there were 6891 (59\%) males and $4844(41 \%)$ females in the conflict zone, compared to $7921(62 \%)$ males and 4875 (38\%) females in the nonconflict zone $(p<0.001)$. The data were not disaggregated by age or gender for the re-treatment TB cases in either zone.

\section{Clinical characteristics \\ TB type and category}

The distribution of tuberculosis types as proportions among newly notified cases (Table 2) shows that the new cases with reported diagnosis by TB type and category (21,131 conflict, 43,826 non-conflict) were more smear positive pulmonary TB in the conflict zone $(63 \%)$ compared to the non-conflict zone $(32 \%, p<0.001)$.

EPTB was the most common type reported in the non-conflict zone comprising $35 \%$ of the new cases, as shown in Table 2. There was a significant difference in the overall $\mathrm{TB}$ smear negative proportions in the conflict zone $(25 \%)$ versus the non-conflict zone $(30 \%$, $p<0.001)$, as shown in Table 1.

Re-treatment cases constituted 7\% and $4 \%$ of all notified cases in the conflict and non-conflict zones respectively. 


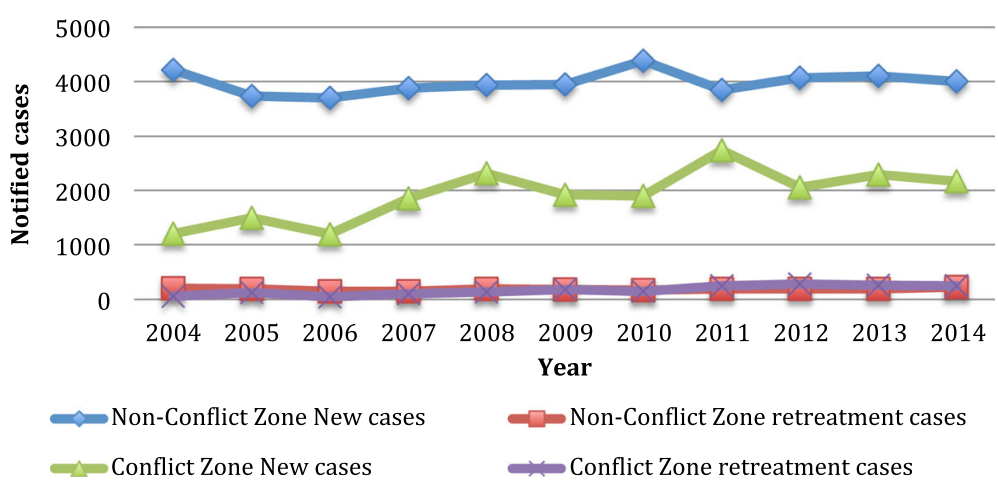

Fig. 1 New and retreatment case notification in conflict and non-conflict zones in Sudan, 2004-2014

Among re-treatment cases, $37 \%$ were classified as retained after the LTFU in the conflict zone compared to $16 \%$ in the non-conflict zone $(p=0.014)$, as seen in Table 1 .

\section{Treatment outcomes}

The LTFU rates among new cases were $7 \%$ and $10 \%$ for the conflict and non-conflict zones, respectively $(p=<0.001)$, as shown in Fig. 2. Reported failures among re-treatment cases were 9\% and 6\% between 2004 and 2014 for the conflict and non-conflict zones respectively $(p<0.001)$. Treatment success rates (TSR) of new cases averaged $66 \%$ in the conflict zone and $65 \%$ in the non-conflict zone between 2004 and $2014(p<0.001)$, as shown in Fig. 3. A steady decrease in TSR of all smear-positive PTB cases was observed from 2010 in both the conflict and non-conflict zones.

\section{Discussion}

To the best of our knowledge, this is the first study describing the notification, characteristics and outcomes of TB cases, between the Darfur conflict region and the Eastern non-conflict zones in Sudan over a ten-year period. Some of the findings are consistent with the hypothesis that conflicts are likely to have a negative impact on TB response measures. However, TB control indicators, including LTFU and treatment success among new TB cases, were worse in the non-conflict zone. Protracted conflicts, ongoing humanitarian crises and associated low expenditure on health are likely to have exacerbated an already unfavourable condition for TB control indicators and disease outcomes.

\section{Challenges for TB control within the conflict zone}

The study identified a lower number of cases and notification rates of new and re-treatment TB in the Darfur conflict zone. This may reflect a vast and inaccessible community within the conflict zone and a considerable gap in the access to healthcare. Poverty and high direct non-medical costs for the patient can lower accessibility

Table 2 Distribution of tuberculosis types as proportions among newly notified cases in conflict and non-conflict zones, Sudan 2004-2014

\begin{tabular}{|c|c|c|c|c|c|c|}
\hline \multirow[b]{2}{*}{ Year } & \multicolumn{2}{|l|}{ Smear-positive* } & \multicolumn{2}{|c|}{ Smear-negative* } & \multicolumn{2}{|c|}{ Extrapulmonary* } \\
\hline & $\begin{array}{l}\text { Conflict 13,283 } \\
(100 \%)\end{array}$ & $\begin{array}{l}\text { Non-conflict } \\
14,016(100 \%)\end{array}$ & $\begin{array}{l}\text { Conflict } 5309 \\
(100 \%)\end{array}$ & $\begin{array}{l}\text { Non-conflict } \\
12,680(100 \%)\end{array}$ & $\begin{array}{l}\text { Conflict } 1963 \\
(100 \%)\end{array}$ & $\begin{array}{l}\text { Non-conflict } \\
15,738(100 \%)\end{array}$ \\
\hline 2004 & 992 (82\%) & 1497 (36\%) & $102(8 \%)$ & $1456(35 \%)$ & $111(19 \%)$ & $1262(30 \%)$ \\
\hline 2005 & 958 (64\%) & 1461 (39\%) & 307 (21\%) & 1198 (32\%) & 226 (15\%) & 1077 (29\%) \\
\hline 2006 & 764 (64\%) & $1338(36 \%)$ & $312(26 \%)$ & $1302(35 \%)$ & $120(10 \%)$ & $1058(29 \%)$ \\
\hline 2007 & 1218 (66\%) & 1385 (36\%) & $474(26 \%)$ & $1240(32 \%)$ & $164(9 \%)$ & $1261(32 \%)$ \\
\hline 2008 & $1740(75 \%)$ & 1393 (35\%) & 365 (16\%) & 1099 (28\%) & $198(9 \%)$ & $1351(34 \%)$ \\
\hline 2009 & 1364 (71\%) & 1292 (33\%) & $375(19 \%)$ & $992(25 \%)$ & $157(8 \%)$ & $1517(38 \%)$ \\
\hline 2010 & 1462 (77\%) & 1259 (29\%) & 202 (11\%) & $1218(28 \%)$ & $206(11 \%)$ & $1731(39 \%)$ \\
\hline 2011 & 1690 (62\%) & 1132 (29\%) & $690(25 \%)$ & $831(22 \%)$ & $198(7 \%)$ & $1652(43 \%)$ \\
\hline 2012 & 1085 (53\%) & 1227 (30\%) & 693 (34\%) & $932(23 \%)$ & $194(9 \%)$ & 1678 (41\%) \\
\hline 2013 & 980 (43\%) & 1066 (26\%) & 969 (42\%) & $1083(26 \%)$ & $196(9 \%)$ & 1695 (41\%) \\
\hline 2014 & 1030 (47\%) & 966 (24\%) & $820(38 \%)$ & 1329 (33\%) & 193 (9\%) & $1456(36 \%)$ \\
\hline
\end{tabular}

*TB patterns were reported as proportions from the total number of notified new cases each year in the conflict zone and non-conflict zone during 2004-2014 


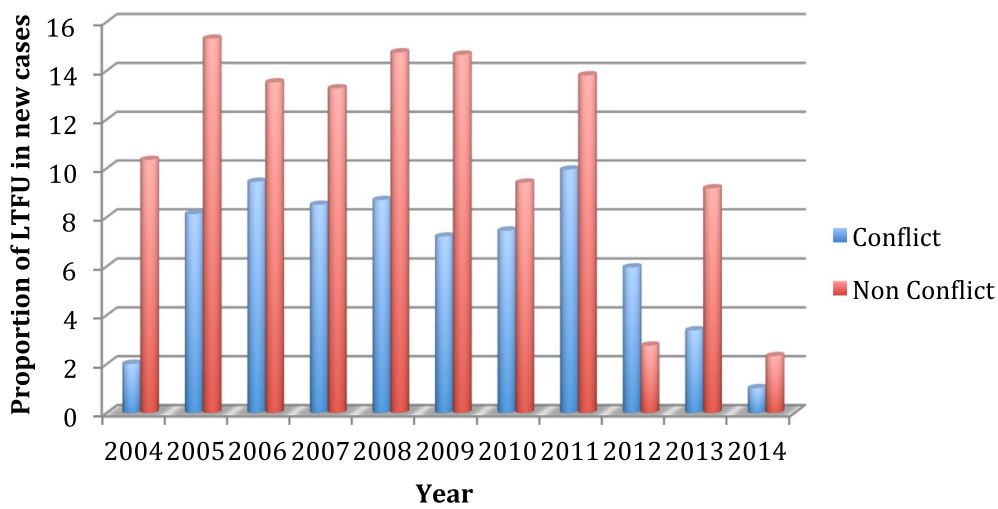

Fig. 2 Lost to follow up rates among new cases in conflict and non-conflict zones Sudan 20,014-2014: * Lost to follow up rates (LTFU) were calculated as the total of LTFU/number of registered cases of treatment outcomes * 100 per year in two zones over 2004-2014

to care in both conflict and non-conflict zones [19]. Nevertheless, turbulence and insecurity in the conflict zone may have further negative effects on the access to healthcare and further exclude communities from timely TB management. Specifications on socio-economic status, residency status, and IDP and refugee camps were not differentiated at the surveillance level. Therefore, no identification regarding these access-associated factors could be obtained for those displaced in the Darfur conflict zone.

There was a very high proportion of smear-positive PTB, comprising $63 \%$ of all newly notified cases in the conflict zone. This proportion is higher than the 56\% positive results reported among 1797 registered patients in the seven states of Sudan between 1998 and 2000 [20]. Here, the crucial finding is that the there is a higher proportion of smear-negative and EPTB cases in the non-conflict zone compared with the conflict zone. As there is a reported healthcare gap in Darfur, the low number of reported EPTB cases in the conflict zones compared to the non-conflict zones could be attributed to the lack of capacity in the disrupted zone to execute adjunctive EPTB diagnosis [15]. This finding needs to be further analysed with regards to the TB associated symptoms and diagnostic criteria measures because this TB pool could be expanded by conflict associated delay in seeking care $[5,21]$.

The identification of all TB disease types in conflict settings can be improved by strengthening the capacity of frontline care in tackling presumptive TB and implementing simple and rapid diagnostics. The proportion of re-treatment cases was $7 \%$ of all notified cases in the conflict zone, which is less than the $16.2 \%$ and $9.1 \%$ reported among the IDPs and the settled population in Khartoum State [22]. There are higher rates of treatment failure and LTFU among the re-treatment cases in the Darfur conflict zone compared to the non-conflict zone. This can increase the risk of drug resistance, which is particularly serious for displaced populations who are already exposed to risk factors associated

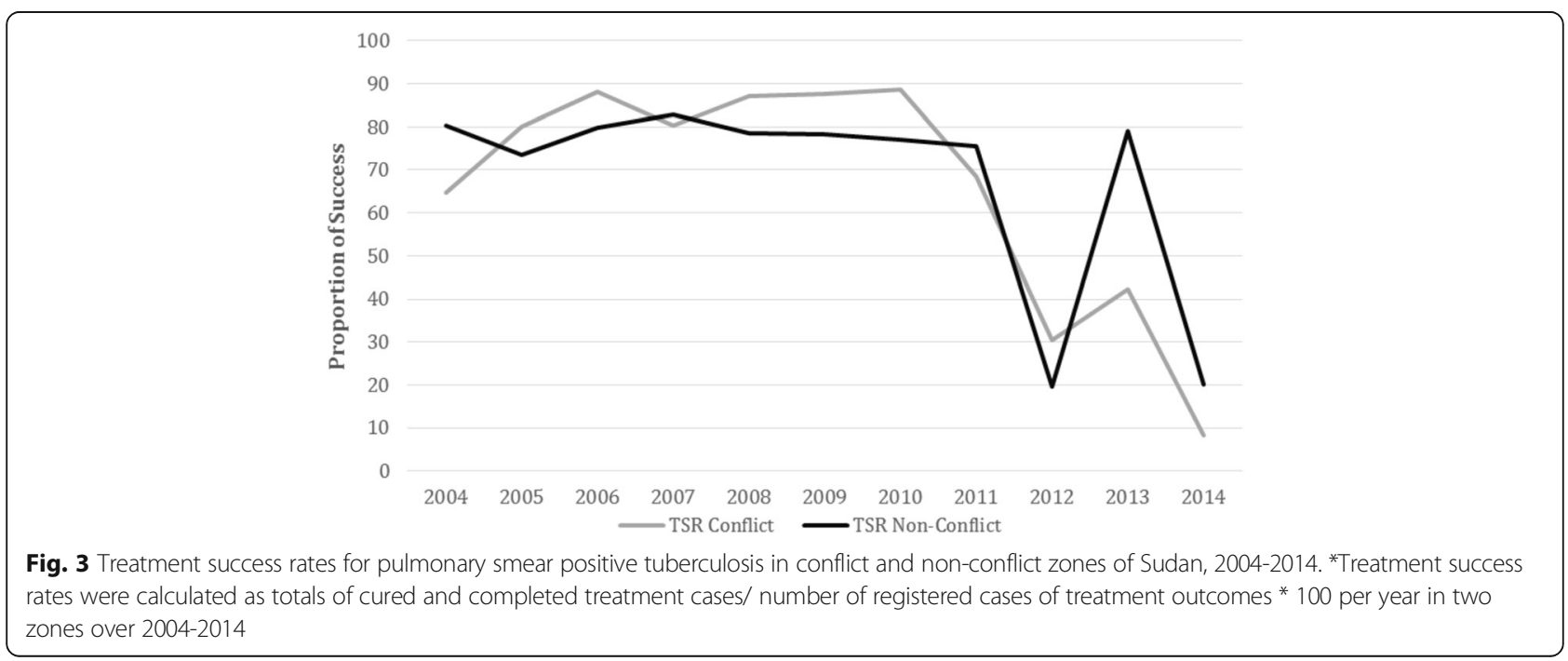


with a poor socio-economic context, which include the risk of higher HIV prevalence while crossing to neighbouring countries [23].

Children make up an important demographic in TB epidemiology, especially those living in poor socioeconomic conditions with low diagnostic capacities [16]. Children constituted 5\% and $10 \%$ of notified cases in the non-conflict and conflict zones respectively. This may be due to the lower cases notified in general within the conflict zone. These figures are less than the $13 \%$ reported in Ethiopia but within the expected range of $5-15 \%$ in low-income countries [24]. The Surveillance data are not fully disaggregated by age, especially among re-treatment cases, highlighting a limitation of the TB programme in addressing childhood TB.

\section{Challenges for TB control within the conflict and non-conflict zones}

We observed high LTFU rates among reported new and re-treatment cases throughout 2004-2014 in both zones (7\% and $10 \%$ in the conflict zone compared to $12 \%$ and $10 \%$ in the non-conflict zone). High LTFU rates can lead to increased disease transmission, greater rates of smear positivity, drug resistance, chronic pulmonary impairment and increased mortality rates [25]. These findings are supported by the study from Galkayo, which found a correlation between the $10 \%$ LTFU rate in Somalia and weak health system management [3].

In Botswana, EPTB was found to be significantly associated with a higher LTFU, which may explain the high proportion of EPTB cases of $36 \%$ in the newly reported cases in the non-conflict zone [26]. A study in Ethiopia has identified living in a rural setting as an independent predicator for LTFU [27]. The rural predominance, and peasant and nomadic populations in both zones indicate the vital need of context-sensitive TB services to reduce the LTFU in both zones.

The TSR of new cases were satisfactory in both zones during 2005-2010, and better rates were observed in the conflict zone. This could be related to the smaller cohort and the higher proportion of smear-positive cases, where the cohort is more likely to be more ailing, and therefore more likely to complete treatment. A comparative study of treatment outcomes in Khartoum State showed significantly higher success rates among the displaced (74\%) compared to settled populations (64\%) [22].

However, a steady decrease in the TSR of all smearpositive PTB cases was observed in both zones from 2010. This is operationally related to the high proportions of unfavourable outcomes, including LTFU and non-evaluated cases. This deterioration in performance in 2010 and the subsequent decrease in TSR in 2012 could be related to challenges in data management and the lack of monitoring at higher surveillance levels.
These pitfalls may hinder sustainable development goals and exacerbate the TB-poverty-vulnerability cycle, especially in conflict settings.

Our findings highlight an urgent need of determined efforts to investigate the associated factors and reasons behind these sub-optimal parameters in both zones. There is a need to revise TB control with "context-sensitive" approaches that simplify pathways to care while improving treatment adherence and tracing strategies. These efforts are needed in both zones to curb the emerging public health threats related to TB.

A limitation of this study is the dependence on routine TB aggregated data, which does not allow for the disaggregation of socioeconomic specifications, displacement, and re-treatment cases by age and gender. Additionally, the lack of data reporting has likely impacted the results to an uncertain degree, because the surveillance does not differentiate between non-functioning and zero notification centres. The strengths of the study include the tenyear timespan of the TB data while assuming a steady population, and surveillance system within both zones.

\section{Conclusions}

There were lower case notification rates and lower proportions of EPTB and smear-negative cases in the conflict zone. However, the TB control indicators, including LTFU and treatment success among new TB cases were found to be worse in the non-conflict zone. Further study is needed to identify determinant factors and causal relations behind these findings, along with context-tailored strategies that increase case finding and promote improved treatment outcomes in both conflict and non-conflict zones. Potential opportunities include the introduction of rapid diagnostic testing and improved frontline healthcare. Local communities could strengthen TB case finding, treatment adherence and contact tracing to avoid LTFU and improve treatment outcomes. Lastly, the inclusion of the place of residence and distance specifications in the surveillance system would support the monitoring of TB burden and access, especially among displaced, refugee, and mobile populations.

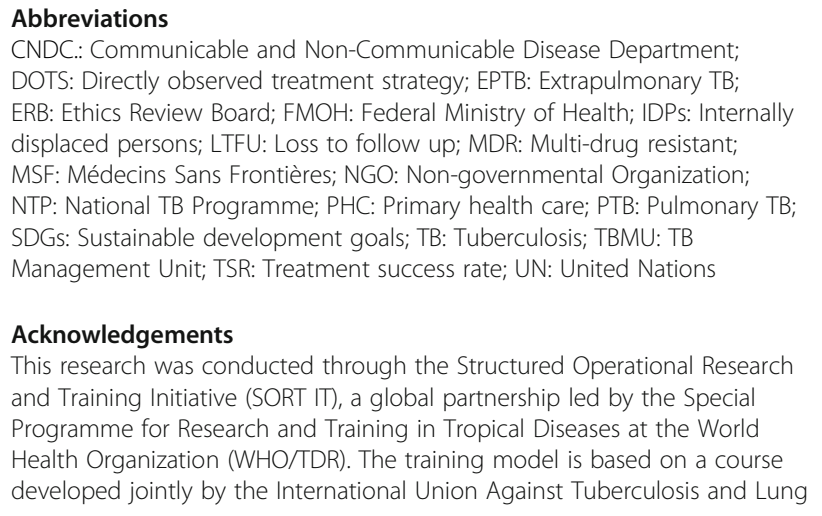


Disease (The Union) and Medécins sans Frontières (MSF). The specific SORT IT program, which resulted in this publication, was implemented by Medécins Sans Frontières, Brussels Operational Center, Luxembourg and the Centre for Operational Research, The Union, Paris, France. Mentorship and the coordination/facilitation of these SORT IT workshops were provided by the Centre for Operational Research, The Union, Paris, France; the Operational Research Unit (LuxOR), AMPATH, Eldoret, Kenya; Institute of Tropical Medicine, Antwerp, Belgium; University of Gondar, Ethiopia; School of Public Health, Johns Hopkins University, Baltimore, Maryland, USA; Luke International, Malawi office; The Centre for International Health, University of Bergen, Norway; and the Northern State Medical University, Arkhangelsh, Russia.

\section{Funding}

The study was funded by the United Kingdom's Department for International Development (DFID), The Union, MSF and La Fondation Veuve Emile MetzTesch (Luxembourg). La Fondation Veuve Emile Metz-Tesch supported open access publications costs. The funders had no role in the study design, data collection, analysis, decision to publish, or preparation of the manuscript.

\section{Availability of data and materials}

Datasets on which the conclusions of the manuscript relied include routinely collected TB data available from The National TB Programme of Sudan. Depositing such programmatic data in a publicly available resource or in a manuscript is sensitive and therefore restricted.

\section{Authors' contributions}

All authors meet the authorship criteria as they have participated sufficiently in the study. All authors participated in the conception and design of the work. The first, fifth and sixth authors collected the data. All authors participated in data analysis and interpretation. The first, second and third authors drafted the manuscript. The first, second, third, fourth, sixth and last author revised the article critically. All authors approved the final version for publication.

\section{Ethics approval and consent to participate}

Permission to carry out the study was obtained from the Sudanese Ministry of Health and ethics approval was obtained from the Ethics Committee of the University of Medical Science and Technology, Khartoum, Sudan. This study fulfilled the exemption criteria set by the Ethics Review Board (ERB) of Médecins Sans Frontières (MSF), Geneva, Switzerland, for a-posteriori analyses of routinely collected data and thus did not require MSF ERB review. The study was also approved by the Ethics Advisory Group of the International Union Against Tuberculosis and Lung Disease, Paris, France (40/16). As this was a study using de-identified, routinely collected aggregated data, informed patient consent was not required.

\section{Consent for publication}

As this was a study using de-identified, routinely collected, aggregated data, informed patient consent was not required.

\section{Competing interests}

The authors declare that they have no competing interests.

\section{Publisher's Note}

Springer Nature remains neutral with regard to jurisdictional claims in published maps and institutional affiliations.

\section{Author details}

${ }^{1}$ The Epidemiological Laboratory, House 34, Street 53, New Extension, P.O.BOX 13595, Khartoum, Sudan. ${ }^{2}$ Médecins Sans Frontières, Luxembourg Operational Research Unit (LuxOR), Luxembourg City, Luxembourg. ${ }^{3}$ Johns Hopkins University, School of Public Health, Baltimore, MD, USA. ${ }^{4}$ Division of Social and Behavioural Sciences, School of Public Health and Family Medicine, University of Cape Town, Cape Town, South Africa. ${ }^{5}$ Directorate General of Planning and International Health - Health Information Federal Ministry of Health-Sudan, Khartoum, Sudan.
Received: 19 December 2016 Accepted: 8 March 2018

Published online: 16 May 2018

\section{References}

1. Kasetjaroen Y, Love E. Prevalence of tuberculosis and service utilization in conflict affected areas of Nepal. J Nepal Health Res Counc. 2005;3:49-57.

2. Gayer M. Conflict and emerging infectious diseases. Emerg Infect Dis. 2007;13:1625-31.

3. Liddle KF, Elema R, Thi SS, Greig J, Venis S. TB treatment in a chronic complex emergency: treatment outcomes and experiences in Somalia. Trans R Soc Trop Med Hyg. 2013;107(11):690-8. https://doi.org/10.1093/ trstmh/trt090

4. Kimbrough W. The burden of tuberculosis in crisis-affected populations: a systematic review. Lancet Infect Dis. 2012;12:950-65.

5. Gele AA, Bjune GA. Armed conflicts have an impact on the spread of tuberculosis: the case of the Somali regional state of Ethiopia. Conf Health. 2010:4:1.

6. Ismail SA. Communicable disease surveillance and control in the context of conflict and mass displacement in Syria. Int J Infect Dis. 2016;47:15-22.

7. Barr RG. The effect of war on tuberculosis. Results of a tuberculin survey among displaced persons in El Salvador and a review of the literature. Tuber Lung Dis. 1994:4:251-9.

8. Acosta CD. Conflict and drug-resistant tuberculosis in Ukraine. Lancet. 2014; 384:1500-1.

9. Cookson ST, Abaza H, Clarke KR, Burton A, Sabrah NA, Rumman KA, Odeh N, Naoum M. Impact of and response to increased tuberculosis prevalence among Syrian refugees compared with Jordanian tuberculosis prevalence: case study of a tuberculosis public health strategy. Confl Health. 2015;9:18. https://doi.org/10.1186/s13031-015-0044-7.

10. Gustafson P. Tuberculosis mortality during a civil war in Guinea Bissau. JAMA. 2001:5:599-603.

11. Feikin DR, Adazu K, Obor D, Ogwang S, Vulule J, Hamel MJ, Laserson K. Mortality and health among internally displaced persons in western Kenya following post-election violence, 2008: novel use of demographic surveillance. Bull World Health Organ. 2010;88(8):601-8. https://doi.org/10 2471/BLT.09.069732

12. Elsony A, Hassanain S, Aithole P. Towards a holistic perception of health: the interrelationships with identity and mobility. In: Hale S, Kadoda G, editors. Networks of knowledge production in Sudan identities motilities and technology: Rowman \& Littlefield; 2016. p. 115-34.

13. Adam MA, Ali HM, Khalil EA. First-line drug resistance patterns of Mycobacterium tuberculosis complex isolates from re-treatment patients from Sudan. J Tuberc Res. 2016:4:98-104.

14. Hassan SO. Drug resistance in Mycobacterium tuberculosis isolates from northeastern Sudan. Br J Med Medical Res. 2012;3:424-33.

15. Nickerson J, Hatcher-Roberts J, Adams O, Attaran A, Tugwell P. Assessments of health services availability in humanitarian emergencies: a review of assessments in Haiti and Sudan using a health systems approach. Confl Health. 2015;9:20. https://doi.org/10.1186/s13031-015-0045-6.

16. UNDP. Human Development Report. United Nation Development Programme 2015

17. OCHA: Sudan Humanitarian Need Overview. United Nations Office for the Coordination of Humanitarian Affairs 2016.

18. Elsony A. The effect of decentralisation on tuberculosis services in three states of Sudan. Int J Tuberc Lung Dis. 2003;7:445-50.

19. Squire SB, Thomson R, Namakhoma I, El Sony A, Kritski A, Madan J. Catastrophic care-seeking costs as an indicator for lung health. BMC Proc. 2015;9(Suppl 10):S4

20. El-Sony A. Treatment results of DOTS in 1797 Sudanese tuberculosis patients with or without HIV co-infection. Int J Tuberc Lung Dis. 2002:6:1058-66.

21. El-Sony A. Relation of grading of sputum smears with clinical features of tuberculosis patients in routine practice in Sudan. Int J Tuberc Lung Dis. 2002;6:91-7.

22. Bøhler M. Tuberculosis treatment outcome and health services: a comparison of displaced and settled population groups in Khartoum. Sudan Int J Tuberc Lung Dis. 2005:9:32-6.

23. Gelaw SM. Socioeconomic factors associated with knowledge on tuberculosis among adults in Ethiopia. Tuberculosis Res Treat. 2016; https:// doi.org/10.1155/2016/6207457 
24. Dangisso MH, Datiko DG, Lindtjørn B. Low case notification rates of childhood tuberculosis in southern Ethiopia. BMC Pediatr. 2015;15:142. https://doi.org/10.1186/s12887-015-0461-1.

25. Marx FM, Dunbar R, Enarson DA, Beyers N. Correction: the rate of sputum smear-positive tuberculosis after treatment default in a high-burden setting: a retrospective cohort study. PLoS One. 2013; https://doi.org/10.1371/ annotation/ea5f2a13-4394-41af-84c8-3e6af4a07770.

26. Enane LA. Loss to follow-up among adolescents with tuberculosis in Gaborone, Botswana. Int J Tuberc Lung Dis. 2016;20:1320-5.

27. Akessa GM, Tadesse M, Abebe G. Survival analysis of loss to follow-up treatment among tuberculosis patients at Jimma University specialized hospital, Jimma, Southwest Ethiopia. Int J Stat Mech. 2015;2015. Article ID 923025. https://doi.org/10.1155/2015/923025.

Submit your next manuscript to BioMed Central and we will help you at every step:

- We accept pre-submission inquiries

- Our selector tool helps you to find the most relevant journal

- We provide round the clock customer support

- Convenient online submission

- Thorough peer review

- Inclusion in PubMed and all major indexing services

- Maximum visibility for your research

Submit your manuscript at www.biomedcentral.com/submit
Biomed Central 